\title{
Galectin-3 induces the phenotype transformation of human vascular smooth muscle cells via the canonical Wnt signaling
}

\author{
LEI TIAN, KAN CHEN, JIATIAN CAO, ZHIHUA HAN, YUE WANG, \\ LIN GAO, YUQI FAN and CHANGQIAN WANG \\ Department of Cardiology, Shanghai Ninth People's Hospital, School of Medicine, \\ Shanghai Jiaotong University, Shanghai 200011, P.R. China
}

Received August 21, 2016; Accepted March 29, 2017

DOI: $10.3892 / \mathrm{mmr} .2017 .6429$

\begin{abstract}
Galectin-3, a galactoside-binding protein, is highly expressed in carotid plaques and plays an important role in the atherosclerotic lesions. The phenotype transformation of vascular smooth muscle cells is the basic pathological change of atherosclerosis. This study investigated the effects of exogenous galectin-3 on the function and phenotype transformation of human umbilical vascular smooth muscle cells (HUSMC). In this study, we treated vascular smooth muscle cells with recombinant galectin-3 and tested its effect on cell proliferation, migration, and phenotype transformation. Our results showed that exogenous galectin-3 promoted human umbilical vascular smooth muscle cells (HUSMC) proliferation and migration. Exogenous galectin-3 enhanced the expression of the smooth muscle synthetic protein osteopontin, smooth muscle contractile proteins calponin and smooth muscle $\alpha$-actin. The galectin-3-induced change in cell phenotype was associated with the activation of canonical Wnt signaling, as measured by $\beta$-catenin axin 2 and cyclin D1 expression. $\beta$-catenin inhibition by small interfering RNA reduced cell proliferation, decreased cell motility, and blocked galectin-3-induced phenotype transformation of human umbilical vascular smooth muscle cells (HUSMC). Our data suggest galectin-3 promotes the phenotype transformation of human umbilical vascular smooth muscle cells (HUSMC) by activating Wnt/ $\beta$-catenin signaling pathway.
\end{abstract}

\section{Introduction}

Atherosclerosis is the primary cause of heart disease and stroke, and it is also one of the main causes of death and disability

Correspondence to: Dr Changqian Wang or Yuqi Fan, Department of Cardiology, Shanghai Ninth People's Hospital, School of Medicine, Shanghai Jiaotong University, 639 Zhizaoju Road, Shanghai 200011, P.R. China

E-mail: changqianwang@hotmail.com

E-mail: moricizine@gmail.com

Key words: galectin-3, HUSMC, phenotype, Wnt, siRNA around the world $(1,2)$. The phenotype transformation of vascular smooth muscle cell (VSMC) plays an important role in the pathology process of atherosclerosis. In the atherosclerotic lesion, there is a large amount of the synthetic phenotype of VSMC in the walls of blood vessel. These synthetic phenotype VSMC tends to form foam-like cells and accelerate lesion progression $(3,4)$. First, these cells secrete a variety of proteins (MMP-2, MMP-9, collagen type I and OPN), which increase lipid content and enhance the accumulation of monocytes and macrophages, second, they are believed to be activated because of enhancing ability of proliferation, immigration, and phagocytosis (3).

Galectin-3 (gal-3), a galactoside-binding protein, can be widely expressed by different kind of cells. Oxidized low-density lipoprotein (oxLDL) can also promote the expression of gal-3 in macrophages (5). In human umbilical vein endothelial cells (HUVEC), gal-3 plays an important role in vascular endothelial growth factor (VEGF)-and basic fibroblast growth factor (bFGF)-mediated angiogenesis (6). More importantly, Gal-3 is an important player in Aldo-induced vascular inflammation and mediates aldo-induced vascular fibrosis, silencing gal-3 blocks aldo-induced collagen type I deposition both in vivo and in vitro (7).

Gal-3 can regulate Wnt signaling (8). Gal-3 is a key regulator in the $\mathrm{Wnt} / \beta$-catenin signaling pathway and interact with axin-2, GSK-3 $\beta$ and $\beta$-catenin immediately (9-11). Furthermore, gal-3 can in direct contact with $\beta$-catenin to stimulate cyclin D1 and c-myc expression (9). Tatsuo even find that human gal-3 sequence has a structural similarity to $\beta$-catenin in the breast cancer cells (10).

Recently, the role of gal-3 in cardiovascular disease has also been widely studied by some researchers (12-17). In the setting of atherosclerotic disease, gal-3 seems to promote atherogenesis. Gal-3 is an useful biomarker which can predict the subsequent infarction after first myocardial infarction (MI) (18). Furthermore, in the absence of gal-3, the development of atherosclerotic pathological change in the ApoE-deficient mouse is reduced (19). Patients with type 2 diabetes and arterial hypertension have higher levels of gal-3 in plasma (20). Gal-3 has been proved to be a promising biomarker for detecting prediabetes and diabetes (21). Until now the mechanism of gal-3 in atherogenesis is still not clear yet, we presumed that gal-3 was a high risk factors of atherosclerosis and could 
promote pathological process of atherosclerosis. Considering the importance of phenotype transformation of SMC, does gal-3 induce atherosclerosis development by modulate cellular phenotype? If it does, what is the mechanism involved?

Thus, in this study, we tried to investigate the effects of exogenous gal-3 inHUSMCs. Furthermore, we examined whether $\beta$-catenin, a reported signaling associated with phenotype transformation of vascular smooth muscle cells, is involved in this gal-3 activity.

\section{Materials and methods}

Reagents. The Dulbecco's modified Eagle's medium (DMEM), fetal bovine serum (FBS), and penicillin/streptomycin (pen/strep, 10,000 U/ml each) were purchased from Gibco (Carlsbad, CA, USA). oxLDL was obtained from Peking Union-Biology Co., Ltd. (Beijing China). TRIzol reagent for RNA isolation was purchased from Invitrogen (Carlsbad, CA, USA). XAV939 was purchased from Sigma-Aldrich (St. Louis, MO, USA). The reverse transcriptase kit (RR037A) and SYBR Premix Ex Taq (DRR420S) were purchased from Takara (Dalian China). The Cell Counting Kit-8 (CCK-8) assay kit was purchased from Dojindo (Kumamoto, Japan). Recombinant human gal-3 was purchased from PeproTech (Rocky Hill, NJ, USA). The primary antibody against gal-3 (no. sc-20157), SMA (no. sc-32251), cyclin D1 (no. sc-8396) and GAPDH (no. sc-48166) were obtained from Santa Cruz Biotechnology, Inc. (Dallas, TX, USA). Anti-phospho GSK3 $\beta$ (Ser9) (no. CST-9322), anti-GSK3 $\beta$ (no. CST-9315), anti-nonphospho (active) $\beta$-catenin (no. CST-4270), and anti- $\beta$-catenin (no. CST-9582) were acquired from Cell Signalling Technology, Inc. (Danvers, MA, USA).The antibody against osteopontin (OPN; no. ab91655), calponin (no. ab46794) and axin2 (no. ab109307) were obtained from Abcam (Cambridge, UK). The goat anti-rabbit secondary antibody (no. A-21109) and the goat anti-mouse secondary antibody (no. A-21058) were provided by Invitrogen. All other chemicals were from commercial sources.

Cells culture. A primary culture of human SMCs was established by explant outgrowth of a segment of human umbilical cord retrieved at the time of caesarean section (22). Endothelial cells were removed by scraping the luminal surface of the vessel with a cotton swab, and the adventitia was mechanically stripped away. Primary cultures were maintained in DMEM supplemented with $20 \%$ FBS and $1 \%$ antibiotics (penicillin/ streptomycin) (all from Gibco). Cells between 4th and 10th passages were used in these experiments. The trail confirmed with the principle of the Declaration of Helsinki and was approved by the Ethics Committee of the Shanghai Ninth Hospital.

siRNA interference. $\beta$-catenin expression was inhibited by transfection with a siRNA specific to $\beta$-catenin. $\beta$-catenin siRNA was transiently transfected into the cells using Lipofectamine ${ }^{\circledR} 2000$ (Invitrogen Life Technologies), according to the manufacturer's instructions. Briefly, $5 \times 10^{5}$ HUSMCs per well were cultured in 6 -well plates to $75 \%$ confluence. The cells were then transfected with 100 pmol siRNA duplexes using $5 \mu$ l Lipofectamine ${ }^{\circledR} 2000$ and $500 \mu 1$ DMEM (reduced serum medium). The process of transfected was without antibiotics. Following a $72-\mathrm{h}$ incubation at $37^{\circ} \mathrm{C}$, the cells were harvested for analysis. The human $\beta$-catenin siRNA sequence was 5'-CATGUGUTGGUAAGCUCUA-3' and the scrambled siRNA sequence was 5'-GCAACAGTTGCAGAGAGGU-3'. They were synthesized by Biotend (Shanghai, China).

Cell proliferation assay. Cell proliferation was measured with the CCK-8 assay kit. In brief, 5,000 cells were plated in each well of a 96-well plate and allowed to attach for $24 \mathrm{~h}$. Then, HUSMCs were subsequently incubated for $0,12,24$ or $48 \mathrm{~h}$ in the presence of gal-3. Subsequently, the plate was incubated with CCK-8 for $4 \mathrm{~h}$ at $37^{\circ} \mathrm{C}$. At last, the absorbance of wave length was taken at $450 \mathrm{~nm}$.

Migration assay. The assay was performed as previously described (23). Migration assays were performed in a chamber, HUSMCs were resuspended in $200 \mu \mathrm{l}$ serum-free DMEM medium and $5 \times 10^{4}$ HUSMCs were loaded into the upper chambers. The lower chamber was filled with $400 \mu 1$ of DMEM in the presence or absence of $10 \mu \mathrm{g} / \mathrm{ml}$ recombinant gal-3. The chamber was incubated at $37^{\circ} \mathrm{C}$ for $24 \mathrm{~h}$. Then, the lower side of the filter was washed with PBS and fixed with $4 \%$ paraformaldeyde. Nuclei were stained with 4',6-diamino-2-phenylindole (DAPI, 1:1,000; Sigma) for $5 \mathrm{~min}$ at room temperature. The cells were counted in three random high-power fields (x100) in each well.

Real-time RT-PCR analysis. Total RNA was extracted using TRIzol reagent (Invitrogen) according to the manufacturer's protocol. Total RNA was reverse-transcribed into cDNA using reverse transcriptase, and quantitative real-time PCR was performed using SYBR-Green master mix, on an Applied Biosystems 7500 real-time PCR system, according to the manufacturer's instructions. Specific primers for human gal-3, $\beta$-catenin, OPN, axin2, calponin, SMA and GAPDH were as follows: Gal-3 forward, 5'-GGCCACTGATTGTGCCTTAT-3' and reverse, 5'-TGCAACCTTGAAGTGGTCAG-3'; $\beta$-catenin forward, 5'-GCCGGCTATTGTAGAAGCTG-3' and reverse, 5'-GAGTCCCAAGGAGACCTTCC-3'; OPN forward, 5'-TGA GTCTGGAAATAACTAATGTGTTTGA-3' and reverse, 5'-GAACATAGACATAACCCTGAAGCTTTT-3'; axin2 forward, 5'-CTCTCTACCTCATTTCCCGAGAAC-3' and reverse, 5'-CGAGATCAGCTCAGCTGCAA-3'; calponin forward, 5'-ATGTGAGGAGGGAAGAGTGTG-3' and reverse, 5'-CGGTTGAAGTGAGCAGAGG-3'; SMA forward, 5'-AGC GTGGCTACTCCTTCGTGAC-3' and reverse, 5'-GCTCGTT GCCGATGGTGATGAC-3'; cyclin D1 forward, 5'-AATGACC CCGCACGATTTC-3' and reverse, 5'-TCAGGTTCAGGCCT TGCAC-3'; GAPDH forward, 5'-TGATGACATCAAGAAGG TGGTGAAG-3' and reverse, 5'-TCCTTGGAGGCCATGTGG GCCAT-3'.

Western blot analysis. Cells were lysed in a lysis buffer containing $150 \mathrm{mM}$ of $\mathrm{NaCl}, 10 \mathrm{mM}$ of Tris ( $\mathrm{pH} 7.5), 5 \mathrm{mM}$ of EDTA, $1 \%$ Triton X-100, $1 \mathrm{mM}$ of PMSF, $10 \mathrm{mg} / \mathrm{ml}$ of leupeptin, $10 \mathrm{mg} / \mathrm{ml}$ of pepstatin, and $10 \mathrm{mg} / \mathrm{ml}$ of aprotinin for $30 \mathrm{~min}$ on ice. The nuclear and cytoplastic protein were separately extracted by using the kit (P 0028; Beyotime Institute of Biotechnology (Shanghai, China). Protein concentrations were 
A

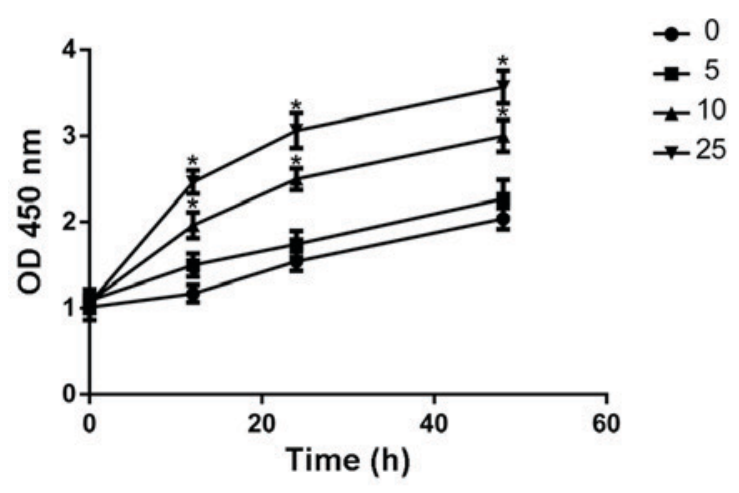

C

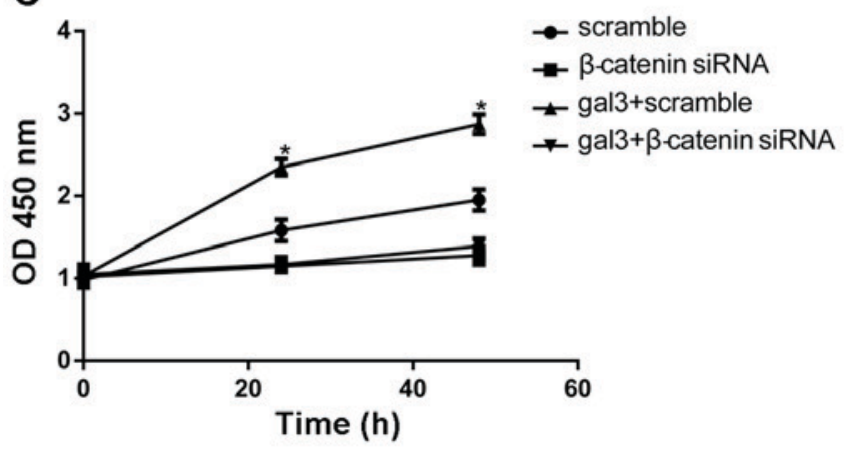

B
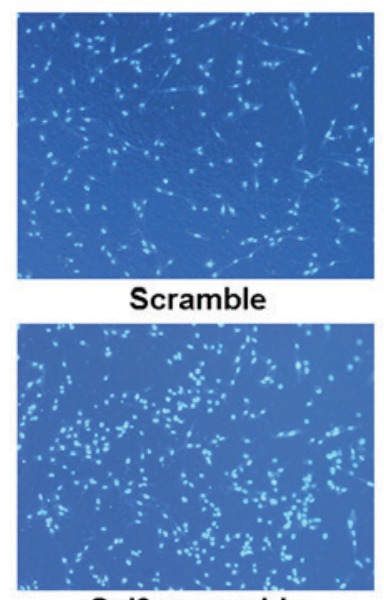

Gal3+scramble

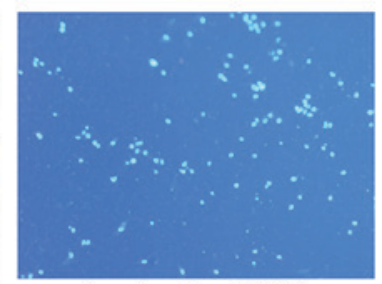

$\beta$-catenin siRNA

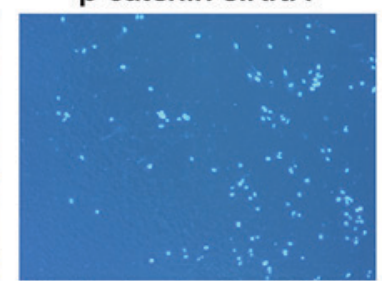

Gal3+ $\beta$-catenin siRNA

D

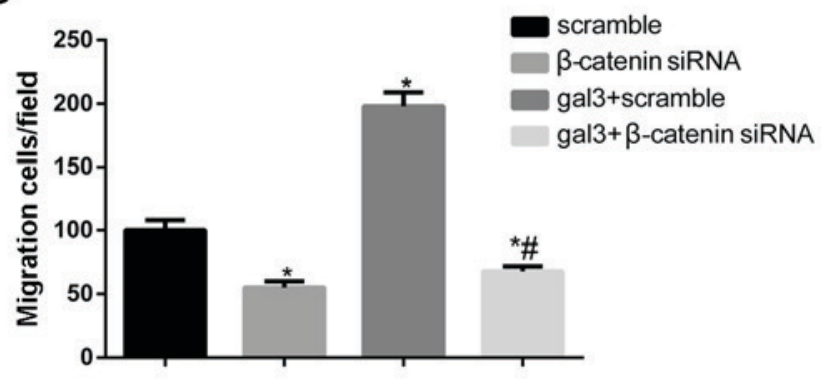

Figure 1. Exogenous gal-3 promotes HUSMCs proliferation and migration. Proliferation assays. Cells were treated with gal-3 over a range of concentration $(0-25 \mu \mathrm{g} / \mathrm{ml}), \mathrm{CCK}-8 \mathrm{kit}$ was added at different time-points to detect cell proliferation (A). Native HUSMCs were defined as control. ${ }^{*} \mathrm{P}<0.05 \mathrm{vs}$. control. After transfection with either control- or $\beta$-catenin-siRNA for $24 \mathrm{~h}, \mathrm{HUSMCs}$ were incubated for $48 \mathrm{~h}$ in the absence or presence of gal-3 (25 $\mu \mathrm{g} / \mathrm{ml})$. CCK-8 were used to detect cell proliferation (C). Cells transfected with scramble siRNA were defined as control. * P $<0.05$ vs. control. Migration assays. Cells migrated to the lower surface of each chamber are shown. After transfection with either control or $\beta$-catenin siRNA for $24 \mathrm{~h}$, migration was tested by a Transwell method. Migrated cells that migrated from the upper chamber to the lower chamber were counted in five nonoverlapping fields under a microscope (x10) (B and D). Bars are represented as the mean $\pm \mathrm{SD}(\mathrm{n}=5)$. ${ }^{*} \mathrm{P}<0.05$ vs. control; ${ }^{*} \mathrm{P}<0.05$ vs. gal-3. Data (mean $\pm \mathrm{SD}$ ) were obtained from three independent experiments.

measured with the BCA Protein Assay (Pierce Biotechnology Inc., Rockford, IL, USA). The lysates $(20 \mu \mathrm{g})$ were electrophoresed on $10 \%$ SDS-PAGE and transferred to nitrocellulose membranes (Merck Millipore, Danvers, MA, USA). The membrane was blocked with 5\% nonfat dry milk in TBST buffer $(100 \mathrm{mM} \mathrm{NaCl}, 10 \mathrm{mM}$ Tris- $\mathrm{HCl}, \mathrm{pH} 7.4$, and $0.1 \%$ Tween-20) for $1 \mathrm{~h}$ at room temperature. The blots were then incubated with various 1000 -fold diluted primary antibodies at a dilution of 1:1,000 in TBST at $4^{\circ} \mathrm{C}$ overnight, and then washed twice with TBST buffer at room temperature and incubated for $1 \mathrm{~h}$ with the appropriate peroxidase-conjugated secondary antibody (1:5,000 dilution). All signals were detected by Odyssey (LI-COR Biosciences, Lincoln, NE, USA). To quantity the protein, band intensity was assessed by Quantity One 4.6.2 software.

Statistical analysis. All data are expressed as the mean \pm SD. Statistics were performed using the SPSS 13.0 software (SPSS, Inc., Chicago, IL, USA). One-way ANOVA followed by the Student-Newman-Keuls post hoc analyses were used. For data that not passed the normality test; non-paramatric ANOVA (Kruskal-Wallis test) was used. A value of $\mathrm{P}<0.05$ was considered statistically significant. All experiments were performed at least three times.

\section{Results}

Exogenous galectin-3 promotes HUSMCs proliferation and migration. First, we used increasing concentrations of gal-3 (up to $25 \mu \mathrm{g} / \mathrm{ml}$ ) to stimulate cells. Cell proliferation was determined at 12,24 , and $48 \mathrm{~h}$ using an CCK-8 assay. As shown in Fig. 1A, the proliferation of HUSMCs was significantly increased in a concentration dependent manner. The Transwell migration assay was used to investigate the effect of recombined gal-3 on cell migration. As shown in Fig. 1B and C, exogenous gal-3 enhanced HUSMCs migration significantly.

Galectin-3 promotes the phenotype transformation of vascular smooth muscle cells. We also investigated the role of exogenous gal-3 in the phenotype transformation of HUSMC. First of all, the HUSMCs were cultured in the DMEM without serum for $12 \mathrm{~h}$. After that, the serum-starved HUSMCs were treated with gal-3 for $48 \mathrm{~h}$. As shown in the Fig. 2, the expression of the smooth muscle synthetic proteins, OPN rose significantly over a range of gal-3 concentration $(0-25 \mu \mathrm{g} / \mathrm{ml})$. Concomitant with the increased OPN expression, the protein markers of contractile phenotype were also increased in gal-3-treated cells, as measured by SMA and calponin expression. 
A

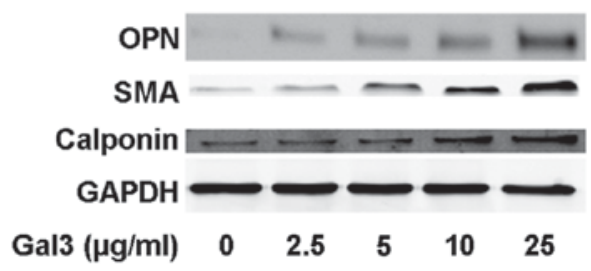

B

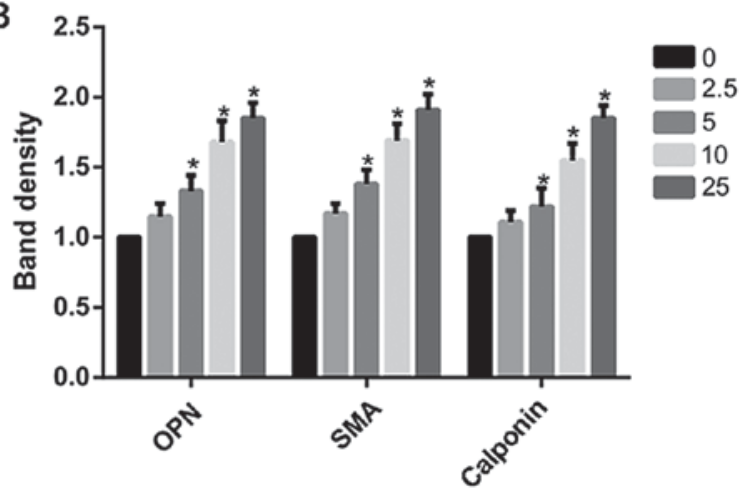

Figure 2. Gal-3 promotes the phenotype transformation of vascular smooth muscle cells. Cells were treated with gal-3 for $48 \mathrm{~h}$ over a range of concentration $(0-25 \mu \mathrm{g} / \mathrm{ml})$, and the expression of OPN, SMA, and calponin were measured by western blotting (A). Respectively densitometric measurement results are given (B). GAPDH protein expression was monitored as controls. Band density of native HUSMCs were defined as control and set to $1,{ }^{*} \mathrm{P}<0.05$ compared with control. Data (mean $\pm \mathrm{SD}$ ) were obtained from three independent experiments.

A

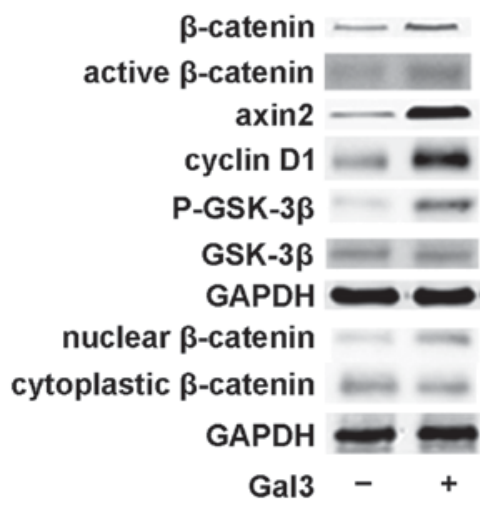

B

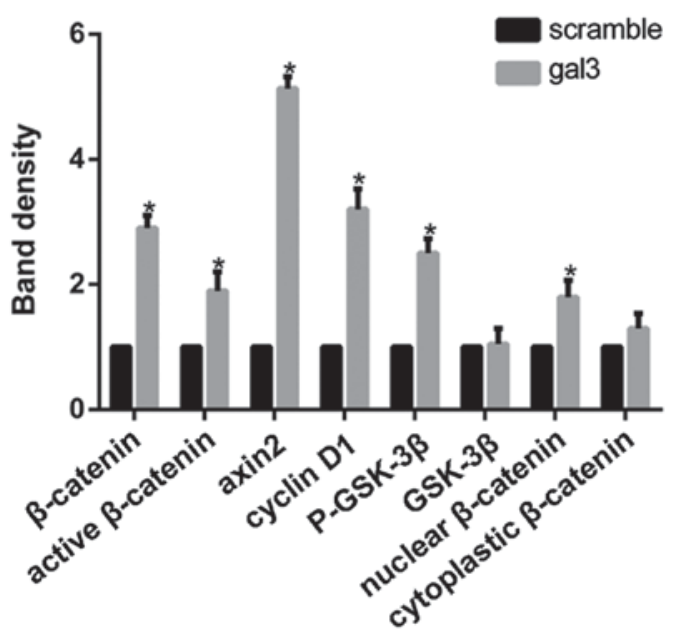

C

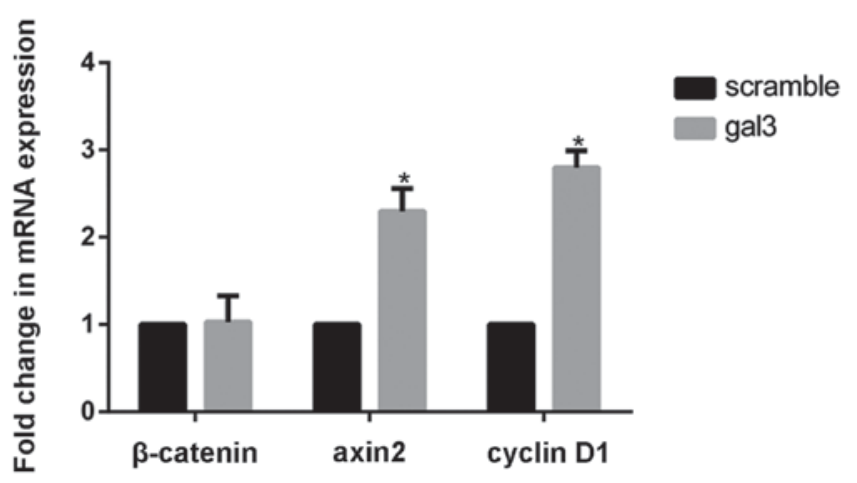

Figure 3. Gal-3 activates canonical Wnt signaling in human umbilical vascular smooth muscle cells. Cells were treated with $25 \mu \mathrm{g} / \mathrm{ml} \mathrm{gal}-3$ for $48 \mathrm{~h}$, and the expression of $\beta$-catenin, cyclin D1 and axin2 were measured by western blotting and real-time PCR (A-C). GAPDH protein expression was monitored as controls. GSK-3 $\beta$, p-GSK-3 $\beta$, nonphosphorylated $\beta$-catenin, nuclear $\beta$-catenin and cytoplastic $\beta$-catenin were measured by western blotting. Band density of native HUSMCs was defined as control and set to $1,{ }^{*} \mathrm{P}<0.05$ compared with control. Data (mean \pm SD) were obtained from three independent experiments.

Galectin-3 activates canonical Wnt signaling in human umbilical vascular smooth muscle cells. Canonical Wnt signal activation could be evaluated by recording $\beta$-catenin protein levels (24). The expression of $\beta$-catenin was tested by western blotting after cells were treated with gal-3. The distribution of $\beta$-catenin in cytoplasm and nucleu were examined by western blot analysis seperately. Gal3 obviousely increased the expression of $\beta$-catenin in nucleu, but it has relatively little effect on the cytoplasmic $\beta$-catenin. To further confirm the activation of canonical Wnt signaling by gal-3, we also detected the expression of axin2 (regulating $\beta$-catenin stability) (25) and cyclin D1 ( $\beta$-catenin target gene) by using realtime-PCR and western blotting. Our results showed that recombinant gal-3 significantly increased expression of axin2 
A

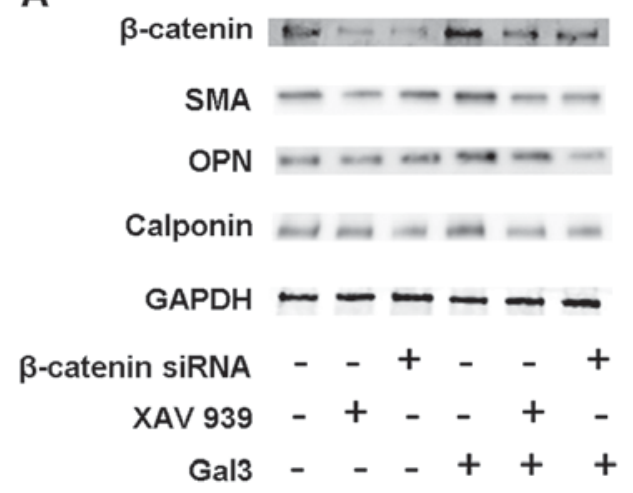

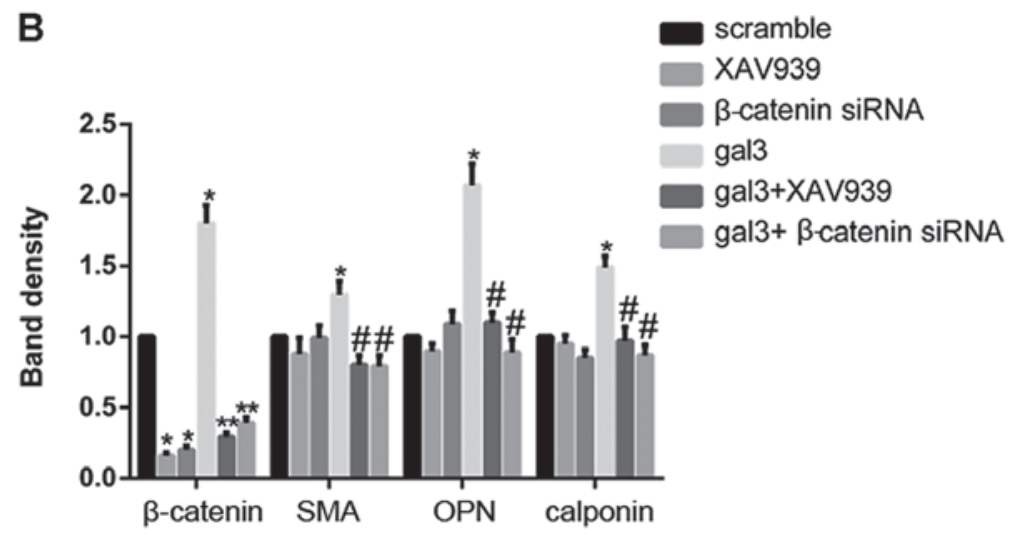

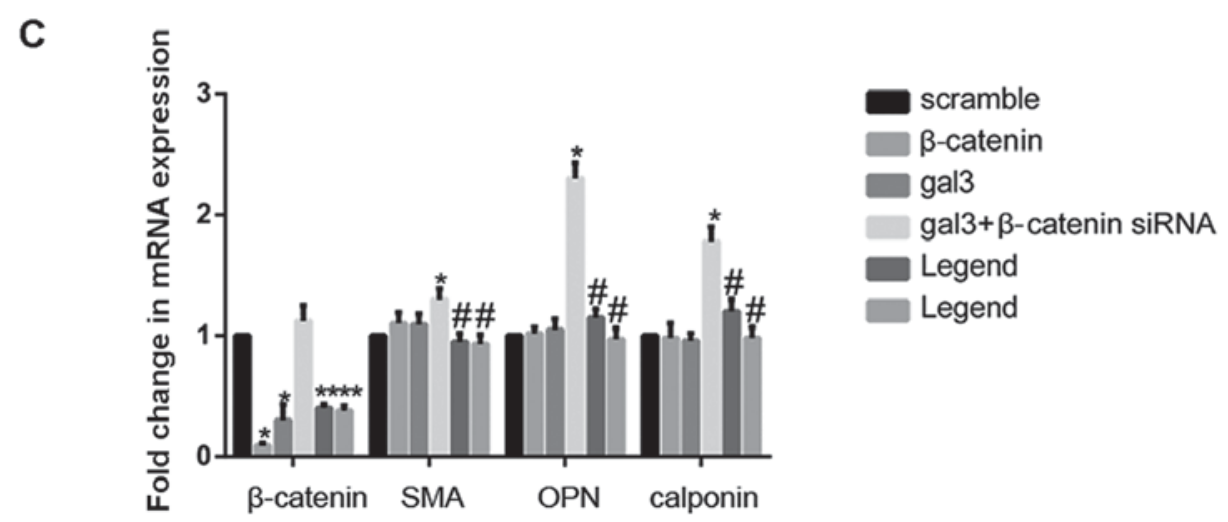

Figure 4. Canonical Wnt/ $\beta$-catenin signaling mediates the effects of gal-3 in HUSMCs. (1) After transfection with either control or $\beta$-catenin siRNA for 24 h, HUSMCs were incubated for $48 \mathrm{~h}$ in the absence or presence of gal-3 (25 $\mu \mathrm{g} / \mathrm{ml})$ or XAV939 (10 $\mu \mathrm{M})$, the expression of $\beta$-catenin, OPN, SMA, and calponin were measured by realtime-PCR and Western blot. Realtime-PCR and Western blot results of $\beta$-catenin, OPN, SMA, and calponin are shown (A and B). Respectively densitometric measurement results are given (C). The GAPDH expression was used for protein level normalization. Band density of HUSMCs which was transfected with scramble siRNA was defined as control and set to $1 .{ }^{*} \mathrm{P}<0.05$ compared with control. ${ }^{\#} \mathrm{P}<0.05$ compared with gal-3. ${ }^{*} \mathrm{P}<0.05$ compared with gal-3 and control.Data (means \pm SD) were obtained from three independent experiments.

and cyclin D1 (Fig. 3). Gal-3 induced a marked increase in the protein expression of nonphosphorylated (active) and total $\beta$-catenin However, the mRNA level of $\beta$-catenin was almost unchanged in the gal-3-treated cells (Fig. 3C). In order to confirm that $\beta$-catenin expression was modulated by gal-3 at the post-translational level, we also detected the activity of GSK-3 $\beta$ which promotes the degradation of $\beta$-catenin. Phosphorylation GSK-3 $\beta$ was 2.5-fold increased by gal-3, while total GSK-3 $\beta$ were almostly unchanged.

Canonical Wnt/ $\beta$-catenin signaling mediates the effects of galectin-3 in HUSMCs. To further evaluate the role of $\beta$-catenin in gal-3-mediated change of HUSMC, the expression of $\beta$-catenin was inhibited by siRNA strategy in HUSMCs. The siRNA of $\beta$-catenin reduced the expression of $\beta$-catenin mRNA and protein by 91 and $83 \%$, respectively. These results indicated that it effectively antagonized the activation of Wnt/ $\beta$-catenin signaling pathway. We then preformed cell proliferation and migration assays on these cells, the silencing of $\beta$-catenin decreased the proliferation and migration of HUSMCs (Fig. 1B and D). Furthermore, the increased ability of migration and proliferation in gal-3-treated cells were also eliminated after silencing of $\beta$-catenin. We then detected the role of $\beta$-catenin in the phenotypic switch induced by gal-3. $\beta$-catenin knockdown efficiently blocked the increase expression of OPN, SMA and calponin induced by gal-3 in both mRNA and protein levels, as demonstrated by western blot and realtime PCR. In order to further confirm the role the Wnt signaling pathway in gal-3 induced phenotype transformation of VSMC, XAV939, a inhibitor of Wnt signaling pathway, was also used. XAV939 similarly attenuated the effect of gal-3 in HUSMCs (Fig. 4A-C).

\section{Discussion}

In this study, we demonstrate, for the first time, that gal-3 can activate the canonical Wnt signaling pathway in HUSMCs. More importantly, we find that gal-3 promote the phenotype transformation of HUSMCs, including increasing proliferation and migration and upregulating a series of phenotype related proteins. While using the strategy of $\beta$-catenin siRNA can obviousely block the gal-3 induces phenotype transformation of HUSMCs. Taken all these data together, we conclude that gal-3 promotes the activation and phenotype transformation of HUSMCs through canonical Wnt $/ \beta$-catenin signaling.

Gal-3 has been reported to affect the function of almost all the cells in the wall of blood vessel. In human umbilical vein endothelial cells (HUVEC), gal-3 is a mediator of vascular endothelial growth factor (VEGF)- and basic fibroblast 
growth factor (bFGF)-mediated angiogenesis $(6,26)$. Gal-3 can also induce the migration of macrophage in mouse (27). Atherosclerosis is characterized by the activation and accumulation of smooth muscle cells in the intimal layer of blood vessels where they internalized a lot of lipids (28). The enhanced proliferation and migration of smooth muscle cells are the symbol of the early pathology of atherosclerosis. In this study, we also showed that exogenous gal-3 can obviously promote the proliferation and migration of HUSMCs. In order to further explore the role of gal-3 in the HUSMCs, we also detected the expression of some widely used SMC marker proteins.

Traditionally, smooth muscle cells are thought of being exist in two totally different phenotypes: Contractile and synthetic phenotype. It is now being recognized that there are a diversity of SMC phenotypes, ranging from contractile to synthetic $(4,29,30)$. In fact, these so-called contractile and synthetic phenotypes should be envisaged as 'idealized' phenotypes. Higher growth rates and stronger migratory activity are usually considered typical of the 'synthetic' phenotype, and OPN is also identified as a synthetic-related protein (3). Actually, recent studies proved that different synthetic and contractile markers could be upregulated at the same time $(4,26)$. In some instances, contractile differentiation can be up-regulated in the 'synthetic' phenotype and contractile differentiation markers may express with matrix synthesis $(28,31)$. In our study, we found that gal-3 stimulated the expression of OPN. Interesting, at the same time, gal-3 also increased the contractile-related protein, calponin and SMA. Therefore, we believe that galectin-3 can promote expression of both smooth muscle synthetic and contractile proteins.

There are two different subclasses of Wnt signalling: The non-canonical pathway (which is $\beta$-catenin dependent) and the canonical pathway ( $\beta$-catenin independent). The activation of non-canonical Wnt pathway can involve the intra-cytoplasmic release of $\mathrm{Ca}^{2+}$ and the activation of Jun $\mathrm{N}$-terminal kinase (JNK). The canonical Wnt signalling pathway involves the inhibition of $\beta$-catenin degradation complex, therefore resulting in the translocation of $\beta$-catenin from the cytoplasm to the nucleus, and binding to downstream target genes. Earlier reports have shown that $\beta$-catenin can regulate the expression of OPN, SMA and calponin expression, induce cell proliferation and migration in many types of cells $(28,32)$. Recently, the role of gal-3 in vascular smooth muscle cells osteogenic differentiation has also been confirmed (32). Thus, we explored the role of $\beta$-catenin in gal-3-treated HUSMCs. In our study, gal-3 activated the canonical Wnt signaling pathway by upregulating the total and nonphosphorylated $\beta$-catenin. We also found that the expression of $\beta$-catenin downstream gene axin2 and cyclin D1 was upregulated by gal-3 $(28,32)$. It further indicated that $\mathrm{Wnt} / \beta$-catenin signaling pathway was activated by gal-3 in the HUSMCs. Our results showed that gal-3 induced the expression of total $\beta$-catenin at protein level but not mRNA level. It is consensus with previous findings. Gal-3, a binding of $\beta$-catenin, increases phosphorylation of GSK-3 $\beta(12,33,34)$. Inactivation of GSK-3 $\beta$ can reduce the degradation of $\beta$-catenin, and increase cellular $\beta$-catenin levels besides, we found that gal-3 indeed increased the phosphorylated level of GSK-3 $\beta$. In order to prove the role of $\beta$-catenin in gal-3-induced phenotype transformation of HUSMCs, we used the siRNA strategy and XAV939 to decrease the expression of $\beta$-catenin. Our results demonstrated that silencing of $\beta$-catenin inhibited gal-3-induced protein expression and blocked gal-3-mediated cell proliferation and migration of vascular smooth muscle cells. Thus, we conclude that recombinant gal-3 induces phenotype transformation of HUSMCs via canonical $\mathrm{Wnt} / \beta$-catenin pathway.

In conclusion, our results show that gal-3 promotes the activation and the phenotype transformation in HUSMCs. This activity is through the canonical Wnt signaling pathway. Recently, gal-3 has been proved to be related to the atherosclerosis and coronary heart disease. As smooth muscle cells plays an important role in a variety of plausible mechanisms of atherosclerosis and chronic heart diseases. Our research could help to clarify the role of gal-3 in the pathological process of atherosclerosis.

\section{Acknowledgements}

This study was supported by grants from the National Natural Science Foundation of China (81270376); Shanghai Hospital Development Center (SHDC12012312); Ministry of Education Science and Technology Development Center (20130073110016); Shanghai Science and Technology Commission (Chinese medicine) (12401905200) and the Fund of Ninth People's Hospital (grant no. 2013A02).

\section{References}

1. Lusis AJ: Atherosclerosis. Nature 407: 233-241, 2000.

2. Karagiannis GS, Weile J, Bader GD and Minta J: Integrative pathway dissection of molecular mechanisms of moxLDL-induced vascular smooth muscle phenotype transformation. BMC Cardiovasc Disord 13: 4, 2013.

3. Doran AC, Meller N and McNamara CA: Role of smooth muscle cells in the initiation and early progression of atherosclerosis. Arterioscler Thromb Vasc Biol 28: 812-819, 2008.

4. Hao H, Gabbiani G and Bochaton-Piallat ML: Arterial smooth muscle cell heterogeneity: Implications for atherosclerosis and restenosis development. Arterioscler Thromb Vasc Biol 23: 1510-1520, 2003.

5. Kim K, Mayer EP and Nachtigal M: Galectin-3 expression in macrophages is signaled by Ras/MAP kinase pathway and up-regulated by modified lipoproteins. Biochim Biophys Acta 1641: 13-23, 2003.

6. Markowska AI, Liu FT and Panjwani N: Galectin-3 is an important mediator of VEGF- and bFGF-mediated angiogenic response. J Exp Med 207: 1981-1993, 2010.

7. Calvier L, Miana M, Reboul P, Cachofeiro V, MartinezMartinez E, de Boer RA, Poirier F, Lacolley P, Zannad F, Rossignol P and López-Andrés N: Galectin-3 mediates aldosterone-induced vascular fibrosis. Arterioscler Thromb Vasc Biol 33: 67-75, 2013.

8. Dumic J, Dabelic S and Flögel M: Galectin-3: An open-ended story. Biochim Biophys Acta 1760: 616-635, 2006.

9. Shimura T, Takenaka Y, Tsutsumi S, Hogan V, Kikuchi A and Raz A: Galectin-3, a novel binding partner of beta-catenin. Cancer Res 64: 6363-6367, 2004.

10. Shimura T, Takenaka Y, Fukumori T, Tsutsumi S, Okada K, Hogan V, Kikuchi A, Kuwano H and Raz A: Implication of galectin-3 in Wnt signaling. Cancer Res 65: 3535-3537, 2005.

11. Song S, Mazurek N, Liu C, Sun Y, Ding QQ, Liu K, Hung MC and Bresalier RS: Galectin-3 mediates nuclear beta-catenin accumulation and Wnt signaling in human colon cancer cells by regulation of glycogen synthase kinase-3beta activity. Cancer Res 69: 1343-1349, 2009.

12. Francia P, Adduci C, Semprini L, Borro M, Ricotta A, Sensini I, Santini D, Caprinozzi M, Balla C, Simmaco M and Volpe M: Osteopontin and galectin-3 predict the risk of ventricular tachycardia and fibrillation in heart failure patients with implantable defibrillators. J Cardiovasc Electrophysiol 25: 609-616, 2014. 
13. de Boer RA, Edelmann F, Cohen-Solal A, Mamas MA, Maisel A and Pieske B: Galectin-3 in heart failure with preserved ejection fraction. Eur J Heart Fail 15: 1095-1101, 2013.

14. Felker GM, Fiuzat M, Shaw LK, Clare R, Whellan DJ, Bettari L, Shirolkar SC, Donahue M, Kitzman DW, Zannad F, et al Galectin-3 in ambulatory patients with heart failure: Results from the HF-ACTION study. Circ Heart Fail 5: 72-78, 2012.

15. Mayr A, Klug G, Mair J, Streil K, Harrasser B, Feistritzer HJ, Jaschke W, Schocke M, Pachinger O and Metzler B: Galectin-3: Relation to infarct scar and left ventricular function after myocardial infarction. Int J Cardiol 163: 335-337, 2013.

16. Sanchez-Mas J, Lax A, Asensio-Lopez MC, FernandezDel Palacio MJ, Caballero L, Garrido IP, Pastor F, Januzzi JL and Pascual-Figal DA: Galectin-3 expression in cardiac remodeling after myocardial infarction. Int J Cardiol 172: e98-e101, 2014.

17. van Kimmenade RR, Januzzi JL Jr, Ellinor PT, Sharma UC, Bakker JA, Low AF, Martinez A, Crijns HJ, MacRae CA, Menheere PP and Pinto YM: Utility of amino-terminal pro-brain natriuretic peptide, galectin-3, and apelin for the evaluation of patients with acute heart failure. J Am Coll Cardiol 48: 1217-1224, 2006.

18. Szadkowska I, Wlazel RN, Migala M, Bajon-Laskowska K, Szadkowski K, Zielińska M, Paradowski M and Pawlicki L: The association between galectin-3 and occurrence of reinfarction early after first myocardial infarction treated invasively. Biomarkers 18: 655-659, 2013

19. Nachtigal M, Ghaffar A and Mayer EP: Galectin-3 gene inactivation reduces atherosclerotic lesions and adventitial inflammation in ApoE-deficient mice. Am J Pathol 172: 247-255, 2008.

20. Seferovic JP, Lalic NM, Floridi F, Tesic M, Seferovic PM, Giga V, Lalic K, Jotic A, Jovicic S, Colak E, et al: Structural myocardial alterations in diabetes and hypertension: The role of galectin-3. Clin Chem Lab Med 52: 1499-1505, 2014.

21. Yilmaz H, Cakmak M, Inan O, Darcin T and Akcay A: Increased levels of galectin-3 were associated with prediabetes and diabetes: New risk factor? J Endocrinol Invest 38: 527-533, 2015

22. Guyton JR, Lenz ML, Mathews B, Hughes H, Karsan D, Selinger E and Smith CV: Toxicity of oxidized low density lipoproteins for vascular smooth muscle cells and partial protection by antioxidants. Atherosclerosis 118: 237-249, 1995.

23. Leavesley DI, Schwartz MA, Rosenfeld M and Cheresh DA: Integrin beta 1 - and beta 3 -mediated endothelial cell migration is triggered through distinct signaling mechanisms. J Cell Biol 121: $163-170,1993$
24. Tickenbrock L, Schwäble J, Strey A, Sargin B, Hehn S, Baas M, Choudhary C, Gerke V, Berdel WE, Müller-Tidow C and Serve $\mathrm{H}$ : Wnt signaling regulates transendothelial migration of monocytes. J Leukoc Biol 79: 1306-1313, 2006.

25. Schaale K, Neumann J, Schneider D, Ehlers S and Reiling N: Wnt signaling in macrophages: Augmenting and inhibiting mycobacteria-induced inflammatory responses. Eur J Cell Biol 90: 553-559, 2011.

26. Nangia-Makker P, Honjo Y, Sarvis R, Akahani S, Hogan V, Pienta KJ and Raz A: Galectin-3 induces endothelial cell morphogenesis and angiogenesis. Am J Pathol 156: 899-909, 2000.

27. Jia W, Kidoya H, Yamakawa D, Naito $H$ and Takakura N: Galectin-3 accelerates M2 macrophage infiltration and angiogenesis in tumors. Am J Pathol 182: 1821-1831, 2013.

28. Carthy JM, Luo Z and McManus BM: WNT3A induces a contractile and secretory phenotype in cultured vascular smooth muscle cells that is associated with increased gap junction communication. Lab Invest 92: 246-255, 2012.

29. Rensen SS, Doevendans PA and van Eys GJ: Regulation and characteristics of vascular smooth muscle cell phenotypic diversity. Neth Heart J 15: 100-108, 2007.

30. Matsushita T, Rama A, Charolidi N, Dupont E and Severs NJ: Relationship of connexin43 expression to phenotypic modulation in cultured human aortic smooth muscle cells. Eur J Cell Biol 86: 617-628, 2007.

31. Rama A, Matsushita T, Charolidi N, Rothery S, Dupont E and Severs NJ: Up-regulation of connexin43 correlates with increased synthetic activity and enhanced contractile differentiation in TGF-beta-treated human aortic smooth muscle cells. Eur J Cell Biol 85: 375-386, 2006.

32. Menini S, Iacobini C, Ricci C, Blasetti Fantauzzi C, Salvi L, Pesce CM, Relucenti M, Familiari G, Taurino M and Pugliese G: The galectin-3/RAGE dyad modulates vascular osteogenesis in atherosclerosis. Cardiovasc Res 100: 472-480, 2013.

33. Kobayashi T, Shimura T, Yajima T, Kubo N, Araki K, Tsutsumi S, Suzuki H, Kuwano H and Raz A: Transient gene silencing of galectin-3 suppresses pancreatic cancer cell migration and invasion through degradation of $\beta$-catenin. Int $\mathrm{J}$ Cancer 129: 2775-2786, 2011

34. Zhang D, Chen ZG, Liu SH, Dong ZQ, Dalin M, Bao SS, Hu YW and Wei FC: Galectin-3 gene silencing inhibits migration and invasion of human tongue cancer cells in vitro via downregulating $\beta$-catenin. Acta Pharmacol Sin 34: 176-184, 2013. 